\title{
QUEM TEM MEDO DA REVOLUÇÃO CAMPONESA? O ANTICOMUNISMO PIAUIENSE E QUESTÃO AGRÁRIA NA DÉCADA DE 1960.
}

\author{
WHO IS AFRAID OF PEASANT REVOLUTION? THE ANTI-COMMUNISM \\ PIAUIENSE AND AGRARIAN QUESTION IN THE DECADE OF 1960.
}

Marylu Alves de Oliveira ${ }^{1}$

\begin{abstract}
RESUMO
O objetivo do presente texto é analisar as representações anticomunistas construídas no Piauí na década de 1960. A análise das representações demonstrou a existência de três vertentes: a conservadora, a religiosa e a da propriedade privada. No entanto, este artigo pretende compreender as representações anticomunistas acerca da propriedade privada, especialmente relacionada à questão agrária. Ao analisar essa vertente, podemos perceber como sua constituição foi enfatizada, defendida e, acima de tudo, determinante para a construção das demais representações anticomunistas. Devido a conjuntura instável da década de 1960, parcela do Estado e da Igreja Católica tomaram suas posições frente ao dilema agrário, e diante do apoio de segmentos destas instituições às organizações camponesas muitos sujeitos foram acusados de serem comunistas. Nesse sentido, o trabalho está divido entre a atuação da Igreja Católica frente aos movimentos sindicais e o apoio do Estado do Piauí às Ligas Camponesas.
\end{abstract}

PALAVRAS-CHAVE: Anticomunismo - Questão Agrária - Piauí - Década de 1960.

\section{ABSTRACT}

The purpose of this text is analyzing the anti-communists representations constructed in the 1960's decade in Piauí. The analysis of representations showed the existence of three parts: the conservative, religious and private property. However, this article aims to understand the anti-communists representations on private property, particularly related to the agrarian question. In considering this aspect, we can see how their formation was emphasized, defended and, above all, decisive for the construction of other anti-communists representations.

Due to the unstable situation in the 1960's decade, part of the state and the Catholic Church took their positions in front of the dilemma agriculture, and in front of the support of segments of these institutions to peasant organizations many people were accused of being communists. In that sense, the work is divided between the Catholic Church in front of the trade union movement and support of the state of Piaui to Peasant Leagues.

KEYWORDS: Anti-communism - Agrarian Question - Piauí - The 1960's decade. 
INTRODUÇÃO

Ao analisar as representações anticomunistas, na década de 1960 , no Estado do Piauí, percebemos a existência de vários discursos concorrentes elegendo o comunismo como principal fator de todos os acontecimentos negativos ocorridos naquele Estado. $O$ anticomunismo não foi importante apenas para os acontecimentos políticos e sociais no Piauí da década de 1960, também foi essencial na construção da cultura política (KUSHINIR e CARNEIRO, 1999/2, p.227) brasileira durante a maior parte do século XX. Alguns grupos dentro da Igreja Católica, na política nacional e local, em parte da corporação militar, no meio rural e em parcelas da sociedade civil organizada, representaram o comunismo como um mal que precisava ser contido. Cada grupo recusou-o como uma possibilidade de regime econômicopolítico para o Brasil, no entanto, cada segmento enfatizava o aspecto negativo que era mais importante no seu combate. Apesar da multiplicidade de interesses que cada grupo possuía nas formulações das representações, estabeleceu-se na memória coletiva (HALBWACHS, 2006) uma espécie de "homogeneidade" negativa sobre o comunismo. Um dos motivos para esse estabelecimento remete às "lutas de representações" onde os grupos lutam para impor, ou tentar impor, a sua concepção de mundo, os seus valores e o seu domínio (CHARTIER, 1990, p.16). Nesse sentido, e apesar da multiplicidade de aspectos que caracterizaram o discurso anticomunista, conseguimos visualizar que as representações anticomunistas que prevaleceram, no Estado do Piauí, giraram em torno de três vertentes: a conservadora, a religiosa e da propriedade privada.

O objetivo do presente artigo é visualizar como a vertente da propriedade privada foi, entre o período de 1961 a 1964, a mais enfatizada, defendida e, acima de tudo, determinante para a construção das demais representações anticomunistas no Estado do Piauí. Contudo, é necessário fazer uma ressalva sobre a análise dessa vertente. As representações anticomunistas que se constituíram em torno da vertente propriedade privada, estavam em sua grande maioria relacionadas a duas questões: Reforma Agrária e estatização de bens. Nos jornais locais, a Reforma Agrária teve maior destaque, segundo a nossa opinião, porque reflete o contexto histórico ao qual 
- Brasil estava atravessando, mergulhado no debate das Reformas de Base, mas também pelas particularidades piauienses, pois este Estado teve como princípio colonizador os grandes latifúndios para a criação de gado. Era o discurso citadino que se fazia sobre o campo, porque a cidade, sendo o ímã catalisador de gente, novidades e avanços técnicos, portanto supostamente superior àquele outro segmento, produziu seu discurso sobre o que era bom e mau para o campo. Se, por um lado, os donos de terras, argumentavam que o campo deveria continuar como sempre esteve, e a desordem que estava ocorrendo era o resultado da penetração de forças estranhas ao meio agrário, motivadas pelos comunistas. Por outro lado, havia uma tentativa de ajudar os trabalhadores rurais a terem uma condição de vida melhor, e é por conta desse apoio que parte da Igreja Católica, membros do governo do Estado e alguns reformistas vão ser acusados publicamente de serem comunistas.

\section{QUEM É DEUS E O DIABO NA TERRA DO SOL? A QUESTÃO DA PROPRIEDADE PRIVADA E O ANTICOMUNISMO NA DÉCADA DE 1960.}

Figura 01

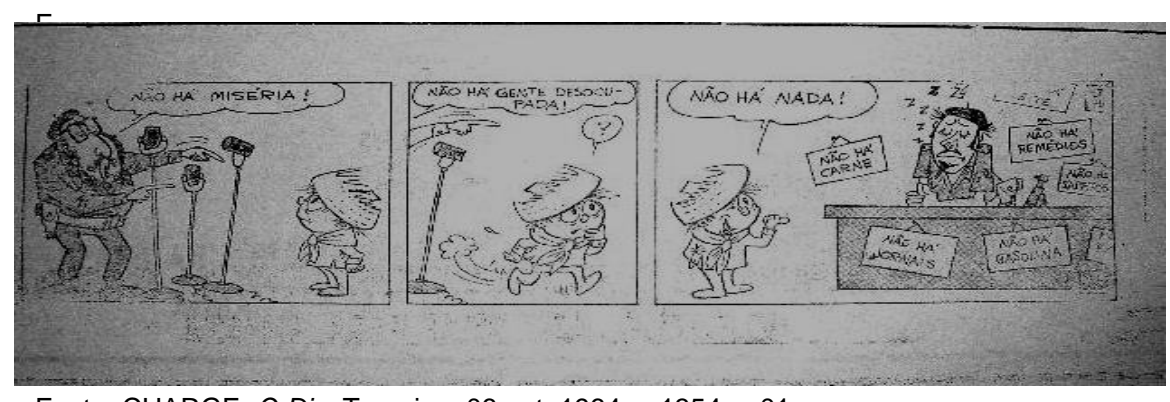

Fonte: CHARGE. O Dia. Teresina, 06 out. 1964, n.1354, p.01.

A charge acima remete a uma preocupação dos anticomunistas da década de 1960: a tentativa dos comunistas de iludirem o homem do campo. Esta charge apresenta-se de maneira educativa, ilustrando o papel dos comunistas. No primeiro quadro, uma figura que podemos apresentar como Fidel Castro, desenhado como se fosse um grande homem, mostra a alguém onde encontrar um sistema sem miséria. $O$ pequeno camponês, sugerido assim pelo chapéu de palha, (em nossa opinião, talvez essa representação de camponês esteja mais relacionada com o trabalhador rural da América Central do que com o agricultor brasileiro) segue a direção apontada por Fidel Castro, 
mas não acreditando totalmente nas palavras ditas, uma vez que no segundo quadro sobre o camponês é desenhado um ponto de interrogação. No terceiro quadro, o camponês vê uma figura em estado sonolento, que supostamente seria Che Guevara, mostrando placas que remetiam a uma situação oposta à anunciada por Fidel Castro. O camponês ironiza, dizendo, a sorrir, a seguinte frase: não há nada!

A charge apresentada ilustra como a introdução de militantes comunistas na orientação do homem do campo, na década de 1960, era uma preocupação naquele momento. Nesse sentido, percebemos que uma grande quantidade de indivíduos se posicionou contrário ao comunismo, levantando como bandeira de luta, a preservação da propriedade privada, em especial a propriedade rural.

Em 1961, a questão agrária estava em voga no Brasil. No Nordeste, as Ligas Camponesas, ${ }^{2}$ no ano de 1955, no engenho Galiléia, município de Vitória do Santo Antão, localizado a 60 quilômetros de Recife, mobilizava os trabalhadores rurais contra a exploração efetuada pelos latifundiários. Com o apoio do Partido Comunista, estes trabalhadores organizaram a Sociedade Agrícola de Plantadores e Pecuaristas de Pernambuco (SAPP) e contavam com o apoio do deputado federal Francisco Julião. Este movimento incentivou o nascimento de outras organizações camponesas, em outros Estados, com o mesmo nome de Ligas Camponesas, inclusive no Estado do Piauí. Reunidos e mobilizados, os camponeses começaram a lutar pela Reforma Agrária.

É nesse mesmo momento, e diante de uma conjuntura instável nacionalmente, que ocupa o cargo de governador do Estado do Piauí, Francisco das Chagas Caldas Rodrigues (1959-1962) ${ }^{3}$. Sua postura era a de aproximação com os movimentos populares, conduzindo seu governo de uma forma distinta das promovidas até aquele momento no Estado do Piauí.

No ano de 1961, a decisão de apoio do governador às Ligas Camponesas no Estado foi uma das iniciativas mais polêmicas de sua administração. O Piauí, desde a colonização, possuiu uma elite detentora da maior parte das propriedades rurais. Em tempos mais recentes, em geral, esses latifundiários se agregavam em um ou outro partido político. As práticas de coronelismo, nas décadas de 1940 e 1950, ainda eram muito comuns no interior do Estado, como relata Marcos Igreja, comunista na década de 1960: 
[...] o meu pai, [...] foi morar no interior, [...] ele ocupou a Ilha Grande da Conceição pra fazer uma roça, e o coronel Gervásio Costa, que era dono das terras, das terras do outro lado do Maranhão, se achava também dono da ilha, e aí foi lá com os jagunços pra botar meu pai pra fora, aí meu pai jogou na cara dele a autorização da capitania dos portos, esse homem ficou com uma raiva, [...] porque nas terras de Gervásio Costa o que prevalecia era a ordem dele, se dava chicotada em caboclo desobediente, comprava o côco pela metade do que os vizinhos compravam, não se pegava em dinheiro, ele dava um valezinho. Você ia, levava dez quilos de côco, que digamos valessem dez reais, você consumia de mercadoria cinco reais aí recebia, vale este cinco reais, [...] os caboclos chamavam (o vale) de "sunguelo", depois ele evoluiu e cunhou uma moeda, acho que ainda hoje tem, ele, o Gervásio Costa, era tão, era um coronel tão forte que cunhou duas moedas lá nas terras dele; do lado do Piauí valia o Gonçalves Dias, 5 Gonçalves Dias, 10 Gonçalves Dias, 15 Gonçalves Dias e do lado do Maranhão era o Novo Nilo, 10 Novos Nilos, 20 Novos Nilos. Não tinha o cruzeiro, que era moeda da época, só se pegava em cruzeiro quando vinha pra capital, e tinha que justificar perante 0 capataz dele, que era muito mais um feitor, às vezes, justificar porque queriam, iariam precisar daquele dinheiro, (por)que o Novo Nilo não valia nem em União, a moeda chamada Novo Nilo não valia nem em União e nem em Teresina, então, tinham que vir com o cruzeiro, mas era essa opressão econômica. Se fosse hoje viveriam, estavam aí nesse negócio de trabalho escravo. Então, meu pai se insurgiu contra - Gervásio Costa e também teve que vir embora de lá. ${ }^{4}$

Essa narrativa ilustra a situação da posse de terra no Piauí, alguns latifundiários, não se achavam donos apenas da terra, mas também da vida dos que nela moravam como agregados. Esse quadro narrado por um filho de agricultor, reflete a questão da posse de terra, em um período recente a este que está sendo analisado neste trabalho. É possível pensar em um quadro completamente diferente deste em apenas uma década? A situação agrária no Estado do Piauí tinha a sua tradição histórica. Nesse sentido, ao apoiar as Ligas Camponesas, e, sobretudo a Reforma Agrária, o governador Chagas Rodrigues nitidamente propôs uma ruptura com uma tradição piauiense.

Apesar do desgosto dos latifundiários com as declarações do governador, os ânimos eram aplacados devido à coligação do partido do governador, PTB (Partido Trabalhista Brasileiro), com a UDN (União Democrática Nacional). No entanto, esse jogo político durou pouco, logo após João Goulart assumir a Presidência da República, a UDN rompe com o PTB em nível local. Os principais motivos foram: o jogo eleitoral que estava previsto para o ano seguinte e o apoio aberto do governador à questão da Reforma Agrária, sendo esse segundo aspecto o acelerador do processo de ruptura da coligação. 
A determinação inovadora do governador e suas alianças políticas vão gerar problemas para a sua administração e, posteriormente, para a sua sucessão, pois a pecha de comunista Ihe foi lançada. De certa forma, isto foi tão marcante em seu governo que, mesmo após o golpe militar-civil de 1964, o ex-governador, Chagas Rodrigues e os que o acompanharam eram relacionados à "praga comunista" que havia se alastrado no Piauí. O discurso anticomunista no Estado já existia bem antes do apoio do governador àquela organização camponesa. No entanto, é a partir da adesão à causa dos agricultores, determinada também pela conjuntura nacional, que o discurso anticomunista, articulado pelos defensores da propriedade privada, intensificouse no Piauí, num primeiro momento, encarnado na figura do então governador Chagas Rodrigues.

Contudo, a década de 1960 também foi um momento de reflexão e de mudanças profundas não apenas para o campo, na Igreja Católica as mudanças se fizeram sentir de forma avassaladora. Deve-se ressaltar que a Igreja Católica nunca foi uma instituição homogênea, no entanto, no Brasil é evidente a tendência a dividir a postura política da Igreja na década de 1960: no primeiro momento como apoiadora do golpe civil-militar de 1964; em um segundo momento, próxima aos movimentos contrários a ditadura, sendo ela, neste segundo momento, um grande ímã na junção de diversos grupos. No nosso entender, a Igreja Católica foi uma instituição determinante em todos os movimentos políticos da década de 1960.

Mesmo com as tentativas do Vaticano de impor uma postura única ao cristão católico, nunca houve por parte dos membros da Igreja Católica uma homogeneidade de pensamento. Este aspecto torna-se claro na década de 1960, principalmente no que tange à questão da terra. Assim como em 26 de julho de 1960, em São Paulo, foi fundado a TFP (Sociedade Brasileira de Defesa da Tradição, Família e Propriedade), instituição que, desde a sua origem, se intitulava anticomunista e favorável à propriedade privada, no mesmo período Dom Helder Câmara, bispo denominado progressista, ia às televisões anunciar o seu apoio à Reforma Agrária. Mesmo não tendo uma posição única, o que é visível, neste momento, é que a Igreja Católica começava a uniformizar a sua preocupação com o campo. 
É nesse mesmo período, de nítidas divisões de posicionamento no seio da Igreja, que chegou ao Piauí Dom Avelar Brandão Vilela. Prelado reconhecido nacionalmente, formulador de vários projetos de ações sociais para o Piauí, Dom Avelar Brandão Vilela também foi um dos defensores da organização dos sindicatos agrícolas no Estado. Essa postura adotada pela Igreja Católica no território piauiense, fez surgir "uma nova realidade que despontava com a criação dos sindicatos, desagradando consideravelmente as elites agrárias piauienses, que chegaram a sugerir a Dom Avelar que mandasse suspender aquelas atividades no campo" (CARVALHO, 2006, p.75).

A proposta de junção de forças entre os camponeses e os donos das terras, para a construção de uma situação mais humana e digna no campo, confronta-se com a proposta de "lutas de classes" divulgadas pelos comunistas. Contudo, mesmo com posições contrárias ao comunismo, Dom Avelar ainda foi acusado de compactuar com as idéias dos comunistas. "A Igreja Católica teve a sua imagem associada ao comunismo pelas elites e por um grupo católico mais conservador, pois o discurso e a prática social em defesa dos oprimidos coincidiram com aquela defendida pelos grupos de esquerda do país" (CARVALHO, 2006, p.56).

Em meio a tentativas de organizações rurais e às propostas de Reformas de Base, surgiram acusações, veladas e explícitas, ao Arcebispo da capital piauiense e ao governador do Estado de serem ou de apoiarem os comunistas. Essas representações anticomunistas, que foram construídas pelos grandes proprietários de terras, que de forma geral se encontravam nas fileiras da política partidária, deram a tônica ao que denominamos de vertente anticomunista relacionada à propriedade privada. Muitos dos anticomunistas da vertente da propriedade privada tinham lugar privilegiado nos espaços midiáticos piauienses. Os jornais escritos, em sua grande maioria, principalmente entre os anos de 1960-1964, noticiavam sobre a questão agrária. Percebemos que muitos dos que escreviam nesses jornais: ou eram donos de terras, como o professor Simplício de Sousa Mendes, que herdou de seu pais muitas terras na região da cidade de União ou, simplesmente, eram apoiadores em decorrência da linha editoral do noticioso de que faziam parte, como foi o caso de José Lopes dos Santos, famoso editor de jornais escritos e radiofônicos no Piauí daquela década. E era principalmente através dos meios 
de comunicação que as representações anticomunistas eram propagadas, aspecto que será analisado a seguir.

Karl Marx, ao propor a supressão da propriedade privada ${ }^{5}$ analisou um mundo urbano, industrial (MARX e ENGELS, 1998, p.21). A cidade era o cenário da revolução comunista. No entanto, empenhados por seus ideais socializantes, os comunistas estabeleceram um regime socialista em países que não possuíam as estruturas industriais propícias para a implantação do regime proposto por Karl Marx. Estes países se transformaram no palco do socialismo real no século XX. De forma geral, como foi no caso russo, havia o predomínio de uma cultura rural. A teoria marxiana não deixou traçada a forma de condução do regime comunista em países industriais. Como, então, poderia ser a condução do regime em países rurais, no qual Marx não havia imaginado uma revolução? A situação das populações foi o que sobrou aos outros países como exemplo, principalmente aos países anticomunistas.

Em decorrência das transcrições de reportagens nacionais sobre a situação da União Soviética e sobre a revolução cubana, a idéia de uma "revolução comunista" tornava-se mais próxima. O interessante das reportagens nesse período é o caráter denunciador. Comparava-se a situação da Rússia, antes da Revolução de Outubro de 1917, a de Cuba no período do ditador Fulgêncio Batista e a conjuntura brasileira naquele momento, visando prevenir as autoridades da possibilidade de acontecer no país uma revolução comunista. Estas "medidas preventivas" eram difundidas pelo território nacional, de maneira que, no Piauí, pode-se verificar nos jornais escritos notas que alertavam para o perigo da "onda vermelha" que se alastrava pelo mundo através da revolução comunista. Olimpio Costa, cronista na década de 1960, publicou o "alerta vermelho", como aponta o trecho abaixo:

Assim, a Revolução russa originou-se das exorbitâncias da aristocracia, em detrimento do equilíbrio popular; também a Revolução cubana foi gerada pelos desmandos de um continuísmo, prejudicando o povo. [...]

A República dos Estados Unidos do Brasil, contrariamente ao que ocorre nos Estados Unidos da América do Norte, se não surgirem providências extremamente necessárias, de parte dos responsáveis pelo governo, será atingida, dentro de pouco tempo, por uma situação capaz de provocar uma revolução de conseqüências imprevisíveis, mas perigosa que a russa e mais sangrenta que a cubana. ${ }^{6}$ 
Vários foram os artigos e crônicas nos jornais do Piauí que denunciavam a situação de miséria da população camponesa dos países comunistas, em especial da União Soviética. As organizações camponesas, como as Ligas Camponesas e os Sindicatos Rurais, que começaram a se organizar no início da década de 1960 no Piauí dão a tônica para a preocupação da implantação do comunismo no Estado. É fácil vislumbrar essa reação nos jornais, mostrando como o processo estava se dando da mesma forma com havia ocorrido na Rússia e em Cuba:

Congresso de Operários e Camponeses, no Piauí: - ao que nos parece, só para compor a expressão - 'Operários e Camponeses', tal qual se deu na Rússia, - onde ao tempo da revolução, também não existia operariado, porque, aquele o país do Leninismo, não era, nem de longe, um país industrializado, mas de agricultores e pequenas fábricas, sem vulto econômico e industrial. ${ }^{7}$

As comparações continuavam a acontecer, no entanto, mostravam quão privilegiados eram os brasileiros. Como fez o Senador, pelo Estado do Piauí, Sigefredo Pacheco, depois de retornar de uma viagem da Europa, onde fez escalas em países comunistas:

Se compararmos o que ganha o operário russo com o salário pago ao operário brasileiro, mesmo tomando-se por base o salário mínimo vigente no Piauí, que é o menor do país, chegamos à conclusão de que o nosso mal pago trabalhador é melhor remunerado do que o russo. Basta dizer que um trabalhador piauiense, com 9 mil cruzeiros mensais, pode adquirir 25 quilos de carne ao preço atual, que é dos mais altos, enquanto o russo apenas adquirirá 15 quilos com os 60 rublos que recebe mensalmente.

- por outro lado - continua Dr. Sigefredo - se levarmos em conta as diferenças de vida na Rússia, com excessivo frio no inverno, em relação ao ameno clima brasileiro, chegamos a conclusão evidente de que o nosso homem do campo tem muito melhor condição de vida. $^{8}$

O discurso do Senador Sigefredo Pachêco, antes de propor alterações para a conjuntura socioeconômica brasileira dos anos de 1960, reclamava por sua conservação, visto que, uma mudança de regime seria inútil, pois a situação do trabalhador brasileiro, segundo o ponto de vista do senador, era melhor do que a situação dos russos após a revolução.

O medo do comunismo se implantar no Brasil, e no Piauí, era uma constante nos jornais que circulavam na cidade de Teresina no período entre 1961 a 1964. Marx era o teórico mais citado nestes periódicos e o fim da 
propriedade relacionada à implantação do comunismo era o tema preferido. Mesmo sendo citado por intelectuais, ou por cronistas eventuais, nunca houve uma reflexão sobre as propostas comunistas com relação ao campo, o que havia era um amontoado de acusações e os exemplos da Rússia, China e Cuba como lugares terríveis para a humanidade.

O campo, no início da década de 1960, como já foi visto antes, era assunto tanto do Estado, como da Igreja e de movimentos interessados na Reforma Agrária. Para os defensores dos latifúndios, a culpa dessa mobilização camponesa se encontrava na educação que estava sendo dirigida aos setores pobres da sociedade, como reflete o texto:

Mas, ninguém se apercebia que o perigo de uma nação
subdesenvolvida consiste, essencialmente, na alfabetização do povo,
que, através das leituras, do conhecimento, reconhece os seus
direitos, passando a encarar a situação em que vive, sob um aspecto
diverso: o que antes era comum e normal passa a se constituir objeto
de estudo, de pesquisas, nascendo os confrontos perigosos, em que
ressaltam as injustiças, as concepções errôneas, os esbulhos
sofridos. $^{9}$

Quem levava as orientações aos camponeses? $\mathrm{Na}$ visão dos anticomunistas eram os comunistas! Se os camponeses agora olhavam para a terra como um problema, era porque havia uma orientação no sentido dessa percepção. Tendo consciência de sua situação os trabalhadores rurais passavam a ver as melhores condições dos habitantes da cidade e até dos trabalhadores urbanos e de certa forma, se vendo como uma parcela inferior. $\mathrm{O}$ homem do campo era inocente, puro e ingênuo, sujeito fácil de ser persuadido pela lábia do comunista esperto e aproveitador, segundo esses observadores. O acesso ao conhecimento mudaria essa situação de ingenuidade, segundo os anticomunistas, faria com que os camponeses tivessem acesso às informações e com a ajuda dos "aproveitadores comunistas" fizessem comparações entre a sua situação do Piauí e a da Rússia antes da Revolução. Nesse sentido, a educação do homem do campo era perigosa. O homem campesino com qualidades passivas, como o do Estado do Piauí, só conseguiria pensar em ocupar terras alheias com a ajuda dos promotores da desordem, como sugere o texto de José Lopes dos Santos, editor de jornais e radialista no período: 
No auge da propaganda subversiva que, então, se fazia, tentando preparar o caboclo pacato do sertão para tomar conta da terra que no dizer dos pregadores e promotores da anarquia e da desordem, era bem comum e a todos devia pertencer, como a água, a luz e o sol, desaparecendo, assim, o instituto da propriedade privada; - no auge dessa propaganda que ainda ecoa nos nossos ouvidos, e através da qual se pretendia transformar o Brasil num satélite de Moscou, ou de Cuba, ou da China Vermelha, tive de envolver-me em uma séria luta profissional, como advogado, visando à defesa de constituintes ameaçados e esbulhados no seu direito de propriedade (SANTOS, 1972, p.133).

Essas palavras são de um editor de um grande jornal de Teresina, que, em seus editoriais, empenhava-se em convocar os proprietários de terra a defender o seu patrimônio contra os comunistas.

Os movimentos que lutavam pela Reforma Agrária, nesse momento, tinham recebido o nome de organizações comunistas, por maior parte de anticomunistas ligados à propriedade privada. A Reforma Agrária, nesse momento, parecia uma desculpa para a implantação de um novo regime, como aponta o jornalista:

O fim é aproveitar-se na ignorância popular - para jogar o povo obscurecido contra a propriedade privada, o patrimônio particular a começar pela propriedade de terra.

O fim não é dar terra ao caboclo, ao agricultor braçal, não; - isto é êngodo, é o meio de enganar o pobre trabalhador, lançá-lo criminosamene, contra os patrões e protetores, - no sentido e nos rumos do comunismo sem moral, sem Deus - subversivo e tirano. ${ }^{10}$

Prevaleceram as representações do comunismo como um mal. Nesse sentido, havia os constantes exemplos, nos jornais locais, da precária situação dos indivíduos que habitavam países comunistas, principalmente os trabalhadores do campo. Houve também uma preocupação com a educação do homem do campo, puro, ingênuo, sendo orientado a invadir terras alheias pelas mentes perversas dos comunistas da cidade. Mas, de todas as representações que foram construídas em torno do comunismo para impedir uma Reforma Agrária no Brasil, a que nos chamou mais atenção foi a posição tomada pelo Senador Sigefredo Pacheco. Em meio à discussão da Reforma Agrária, o Senador falou sobre a situação do campo nos países comunistas que ele havia visitado: 
sua casa. Nessa pequena área pode lavrar a terra dispondo livremente de seu produto. E pode possuir uma vaca. Apenas uma.

- Perguntei ao presidente da Karkov - declara textualmente o representante do Piauí no Senado da República: "O possuidor de uma vaca daqui a dez anos certamente já disporá de dez vacas". A resposta foi rápida: "Todos os produtos da vaca são vendidos ao Governo. E ao cabo de dez anos o camponês continua apenas com uma vaca".

Face a essa situação argumenta o doutor Sigefredo:

Se considerarmos a situação do agregado brasileiro, que além de usufruir a terra como bem entende, pagando ao proprietário somente um quinto da produção, e ainda podendo criar o seu gado bovino, ouvino e caprino etc...sem quem ninguém lhes reclame direito, ficamos sem compreender porque no Brasil se faz tanta celeuma em torno das Ligas Camponesas, Sindicatos e outros organismos de fonte duvidosa que giram em torno da Reforma Agrária, num país onde dois têrços da terra continuam despovoados. ${ }^{11}$

A situação dos países comunistas, bem como a de seus trabalhadores rurais, segundo o Senador Sigefredo Pachêco, não poderia ser exemplo para os trabalhadores brasileiros, já que a condição do agregado no Brasil era muito mais favorável do que a de um pequeno proprietário de terra em um país comunista. Essas organizações rurais, para o Senador, nem precisavam fazer alvoroço, já que o Brasil era praticamente um país despovoado. Esse exemplo, dado por Sigefredo Pacheco, é a representação do que seria a vida do camponês brasileiro caso o comunismo fosse implantado no país.

\section{CONSIDERAÇÕES FINAIS}

A questão agrária no Piauí, assim como no Brasil, foi fator de disputas políticas e ideológicas, principalmente no período de 1961 a 1964. As representações anticomunistas que se constituíram em torno da vertente da propriedade privada estavam diretamente relacionadas à discussão da Reforma Agrária. Por estarem dispostos a apoiarem os movimentos do campo, como as Ligas Camponesas e os sindicatos agrícolas, parte da Igreja Católica e do Estado foi tachada de ser ou de apoiar comunistas. Os discursos que circulavam nos jornais locais, pregavam um clima de tensão, que deveria ser acalmado, por ameaça de acontecer aqui o que já havia acontecido em países como a Rússia, Cuba e China. O espaço do campo deveria se dobrar ao saber da cidade. O campo foi visto sempre como um espaço de ingenuidade e passividade, não podendo cair nas mãos dos comunistas da cidade. $O$ 
comunismo, certamente, era percebido como um mal, e essa representação é a que vai rondar todas as representações anticomunistas durante vários anos.

\section{REFERÊNCIAS BIBLIOGRÁFICAS}

CARVALHO, Maria do Amparo Alves de. História e Repressão: fragmentos de uma memória oculta em meios às tensões entre lgreja católica e o regime militar em Teresina: UFPI. Teresina, 2006. 229p. Dissertação de Mestrado.

CHARTIER, Roger. História cultural: entre práticas e representações. Tradução: Maria Manuela Galhardo. Lisboa, São Paulo: DIFEL, BERTRAND. 1990.

DABAT, Christine Rufino. "Depois que Arraes entrou, fomos forros outra vez": Ligas Camponesas e Sindicatos de trabalhadores rurais: a luta de classes na zona canavieira de Pernambuco segundo os cortadores de cana. In.: Clio. Revista de Pesquisa Histórica. Recife: editora Universitária da UFPE, n. 22, 2006. p.149-188.

HALBWACHS, Maurice. A memória coletiva. Tradução: Beatriz Sidou. - São Paulo: Centauro, 2006.

KUSHINIR, Carina e CARNEIRO, Leandro Piquet. As dimensões subjetivas da política cultural, política e antropologia. In.: Revista de Estudos Históricos. no 24, Rio de Janeiro, 1999/2.

MARX, Karl; ENGELS, Friedrich. O Manifesto do Partido Comunista. In: REIS FILHO, Daniel Aarão (Org). O manifesto comunista 150 anos depois. São Paulo: Perseu Abramo, 1998

MEDEIROS, Antonio José. Movimentos Sociais e participação política. Teresina (PI), CEPAC, 1996.

SANTOS, José Lopes. Votos e discursos. Teresina: Cannes Publicidade, 1972, p.133. 
TAVARES, Zózimo. 100 fatos do Piauí no século 20. Teresina: Halley, 2000. $122 p$.

\footnotetext{
1 Mestra em História pela Universidade Federal do Piauí. Atualmente trabalha como pesquisadora para instituições privadas na cidade de Teresina (PI) e faz parte da comissão científica do Congresso Internacional de História e Patrimônio Cultural, Teresina (PI). Email: marylu.oliveira@gmail.com.
}

2 A fundação e organização das Ligas Camponesas pelo Partido Comunista remete à década de 1940. Sobre as Ligas Camponesas ver: DABAT, Christine Rufino. "Depois que Arraes entrou, fomos forros outra vez": Ligas Camponesas e Sindicatos de trabalhadores rurais: a luta de classes na zona canavieira de Pernambuco segundo os cortadores de cana. In.: Clio. Revista de Pesquisa Histórica. Recife: editora Universitária da UFPE, n. 22, 2006. p.149-188.

${ }^{3}$ Em 1959 é eleito governador do Piauí, Francisco das Chagas Caldas Rodrigues, candidato da oposição pela coligação PTB-UDN. Chegou ao poder devido a uma fatalidade, a morte de Demerval Lobão e Marcos Parente, candidatos a governador e senador pela oposição. $O$ acidente automobilístico que tirou as vidas dos dois políticos, que viajavam, para fazer um comício na cidade de Água Branca, ficou conhecido como Desastre da Cruz do Cassaco, e a morte dos candidatos, provocou uma comoção na população piauiense. Porém, o clima foi bem explorado pelas lideranças oposicionistas, José Cândido Ferraz e Matias Olympio, que, para substituir o candidato a governador que morrera, indicaram o parnaibano Chagas Rodrigues. Sobre esse assunto ver: MEDEIROS, Antonio José. Movimentos Sociais e participação política. Teresina (PI), CEPAC, 1996; TAVARES, Zózimo. 100 fatos do Piauí no século 20. Teresina: Halley, 2000. 122p.

${ }^{4}$ IGREJA, Marcos de Paiva. Entrevista concedida a Francisco Alcides do Nascimento e Marylu Alves de Oliveira. Teresina, 2005.

${ }^{5}$ Segundo Karl Marx, para que o proletariado conseguisse derrubar o domínio burguês era necessário suprimir a propriedade privada. Na teoria marxiana o que caracterizava a luta comunista não era apenas supressão da propriedade em si, mas a supressão da propriedade burguesa. E, mais contundente, assegurou Karl Marx: "Neste sentido, os comunistas podem resumir a sua teoria em uma única expressão: supressão da propriedade privada". MARX, Karl; ENGELS, Friedrich. O Manifesto do Partido Comunista. In: REIS FILHO, Daniel Aarão (Org). $O$ manifesto comunista 150 anos depois. São Paulo: Perseu Abramo, 1998, p.21

${ }^{6}$ COSTA, Olimpio. A Origem das Revoluções. O Dia. Teresina, 11 mar. 1962, n. 957, p.01.

7 MENDES, Simplício de Sousa. Congresso de Operários e Camponeses. Folha da Manhã. Teresina, 30 abr. 1961, n.964, p.04.

${ }^{8}$ SIGEFREDO Pachêco fala a O Dia sôbre União Soviética. O Dia. Teresina, 21 nov. 1963, n.1.143, p.01.

${ }^{9}$ BRASIL, Asfalto e Comunismo. O Dia. Teresina, 26 nov. 1961, n.928, p.01.

10 MENDES, Simplício de Sousa. Quem Cultiva Colhe. Folha da Manhã. Teresina, 21 mar. 1962, n.1.209, p.06.

11 SIGEFREDO Pacheco fala a O Dia sobre União Soviética. O Dia. Teresina, 21 nov. 1963, n.1.143, p.01

ARTIGO RECEBIDO EM 05/02/2009. APROVADO EM 07/03/2009. 